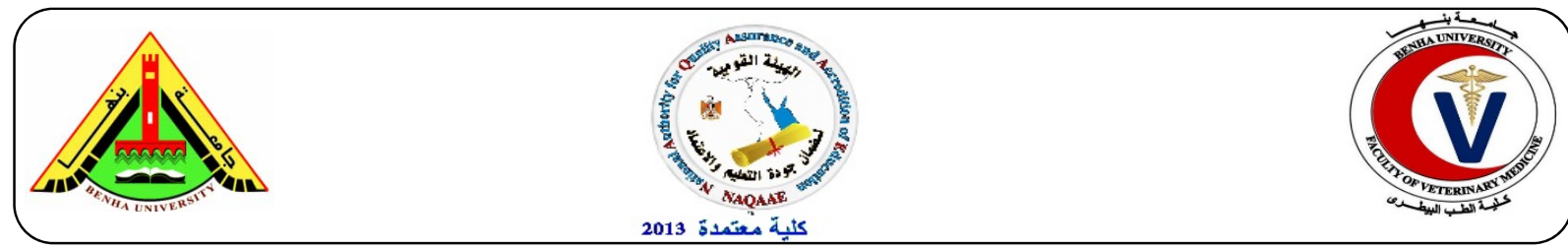

\title{
Bacteriological and Molecular studies on Methicillin-Resistant Staphylococcus aureus (MRSA) isolated from chicken meat and its products in Kaliobia Governorate
}

\author{
${ }^{1}$ Ashraf, A. Abd El Tawab, ${ }^{2}$ Ahmed, A. A. Maarouf, ${ }^{1}$ Fatma I. El-Hofyand ${ }^{3}$, Dina, H. Mousa \\ ${ }^{1}$ Bacteriology, Immunology and Mycology Dep., Fac. Vet. Med. Benha Univ. ${ }^{2}$ Animal Health Research \\ "Benhabranch", ${ }^{3}$ veterinarian.
}

\begin{abstract}
A B S T R A C T
The study was performed on 175 random samples of fresh broiler chicken and chicken meat products viz: Chicken burger; chicken luncheon; chicken kofta and chicken sausage (35 for each), collected from different shops at Benha city, kaliobia government. The sample were examined for detection the prevalence of Staphylococci with special reference to $S$. aureus and MRSA, beside the phenotypic characterization of the isolated S. aureus strains and detection of their virulence genes in them. The bacteriological examination revealed the isolation of 98 Staphylococcus species including 41 S.aureus; 54 S. epidermidis and 3S. chromogenes. In addition, all 41 isolated S. aureus were coagulase positive strains, while, the other isolated Staphylococcal strains (57) were coagulase negative ones. Moreover, the results of SET- RPLA test revealed that 5 S. aureus strains out of 10 randomly examined strains were enterotoxigenic and classified according to type of toxin into (3A; $1 \mathrm{~B} \& 1 \mathrm{C})$. The sensitivity tests for the isolated $S$. aureus showed strains indicated high resistance to methicillin followed by oxacillin; Nalidixic acid; Ampicillin; Amoxicillin; Cefotaxime and Tobramycin, respectively. Meanwhile, they were highly sensitive to Gentamycin; Enrofloxacin; Norfloxacin; Lomefloxacin and Ciprofloxacin. PCR results cleared that, femA; mecA and $h l b$ virulence genes were detected in all 5 S. aureus studied strains. Meanwhile, ica A was detected in 4studied strains; enterotoxin A (sea) was detected in 2 studied strains chicken meat and chicken kofta samples only and leukocidin $(p v l)$ virulence gene was detected in 1 studied strain of chicken meat sample.
\end{abstract}

Keywords: Chicken meat products, bacteriological evaluation, S. aureus, MRSA, PCR, virulence factors.

(http://www.bvmj.bu.edu.eg)

(BVMJ-31(1): 64-72, 2016)

\section{INTRODUCTION}

Poultry meat is a common vehicle of $S$. aureus that considered as one of the most important causes of foodborne outbreaks in people (Losito et al., 2005), 2005). Staphylococci are Gram-positive cocci, form grape-like clusters on Gram's stain, non-motile, non-spore forming facultative anaerobes that grow by aerobic respiration or by fermentation. Thus, S. aureus is considered the third-most important cause of food-borne disease in the world (Liu et al., 2006; Normanno et al., 2007) and has two aggravating characteristics, toxin production and antimicrobial resistance as well as proteolytic and lipolytic activity at $+20^{\circ} \mathrm{C}$, causing meat spoilage (Gundogan and Devren, 2010). The methicillin-resistant S. aureus (MRSA) is mainly attributed to the presence of mecA gene, located on one of Staphylococcal cassette chromosomes mec (SCCmec), that encodes penicillin-binding protein 2a (PBP2a) with a low affinity for essentially all beta-lactam antimicrobials resulting in difficult treatment of infections (Pinho et al., 2001; Thaker et al., 2013; Weese et al., 2010). The methicillin-resistant $S$. aureus (MRSA) is known to be one of the most prevalent nosocomial pathogens throughout the world and is capable of causing a wide range of food poisoning, pneumonia, post-operative wound infections and nosocomial infections (Cuny et al., 2010; Hoerlle and Brandelli, 2009).

In recent years, methicillin-resistant $S$. aureus (MRSA) has been identified in domestic animals and animal-derived food products worldwide (Bhargava et al., 2011; Hanson et al., 2011; Saleha and Zunita, 2010). Of the various food products surveyed, chicken and chicken products are widely known to be important reservoir and main source of MRSA in humans (Abdalrahman et al., 2015; Aklilu et al., 2016; Fessler et al., 2011). The pathogenicity of $S$. aureus could be attributed to the virulence factors the bacteria produce. These virulence factors include, intracellular adhesion (icaA); toxins (enterotoxins, toxic shock syndrome 
toxin-1, Panton-Valentine Leukocidin); hemolysin; coagulase, thus clot blood; protease; hyaluronidase, and staphylokinase (Abdalrahman et al., 2015; Bokarewa et al., 2006; Dinges et al., 2000; Lin and Peterson, 2010). S. aureus produce disease when the bacteria contaminate food, produce some enzymes which are implicated with Staphylococcus invasiveness and many extracellular substances some of which are heat stable enterotoxins that renders the food dangerous even though it appears normal and extensive cooking can be killed the bacteria but the toxins may not be destroyed because most of them are gene based i.e. they can be carried on the plasmid (Prescott et al., 2005). The Staphylococcal enterotoxins (SEs) mainly, sea is responsible for the symptoms that associated with Staphylococcal food poisoning (Balaban and Rasooly, 2000; Llewelyn and Cohen, 2002). As Egypt has a large chicken production industry, few studies have been applied on S. aureus, especially MRSA; in them, that constitutes serious problems for consumers.

Therefore, such study was performed for detection the prevalence of Staphylococci with special reference to $S$. aureus and MRSA, beside the phenotypic characterization of the isolated $S$. aureus strains and detection of some virulence genes.

\section{MATERIAL AND METHODS}

\subsection{Samples collection:}

A total of 175 random samples of fresh broiler chicken and chicken meat products viz: Chicken burger; chicken luncheon; chicken kofta and chicken sausage ( 35 for each), were collected from different shops at Benha city for studying their contamination with Staphylococci.

\subsection{Bacteriological examination}

Accurately, 25 grams of each sample under examination were prepared for bacteriological examination following (APHA, 2001).

\subsubsection{Isolation and identification of Staphylococci strains:}

Isolation and identification of Staphylococci strains from different samples according to Quinn et al. (2002) and (Arora, 2003) as follow: One ml of prepared sample was inoculated into nutrient broth and incubated aerobically at $37^{\circ} \mathrm{C}$ for 12 hours. A loopful from incubated nutrient broth was streaked on $7 \%$ salted nutrient agar and incubated for 24 hours at $37^{\circ} \mathrm{C}$. Then the following tests (Oxidase test, Catalase test and Coagulase test) were performed on yellow convex colonies. The colonies that gave (Oxidase $-\mathrm{ve}$, Catalase $+\mathrm{ve}$,
KOH $3 \%$-ve and Coagulase +ve \& -ve) were taken and cultivated on the following media: Baird Parker agar; Mannitol salt agar; Milk salted agar and Blood agar and incubated for another 48 hours at $37^{\circ} \mathrm{C}$. Suspected colonies (black colonies with yellow halo around them on Baird-Parker agar; yellow colonies surrounded by halo zone on Mannitol salt agar; yellow colonies and turned media to colorless on $7 \%$ salted milk agar and white or yellow, smooth round and shiny colonies on blood agar) were picked up and kept in semisolid agar. The purified isolates of Staphylococci species were morphologically identified by Gram stain and biochemical tests.

\subsubsection{In-Vitro anti-microbial sensitivity test:}

The isolated S. aureus strains were subjected to the sensitivity test against different antibiotics, using the disc and agar diffusion method (Finegold and Com, 1982).

\subsubsection{Detection of enterotoxins producing isolates by SET-RPLA technique (Igarashi et al., 1986). \\ 2.2.4. Virulence genes of S. aureus detection by PCR:}

PCR was applied by using 6 sets of primers for detection of 6 virulence genes that may play a role in virulence of $S$. aureus. These genes were factor essential for methicillin- resistance A (femA), (mecA), leukocidin ( $p v l), \beta$ - haemolysin (hlb), intra - cellular adhesion (ica $A$ ) and enterotoxin A (sea).It was applied on 5 random isolated S. aureus (one isolate from each sample) following QIAamp® DNA Mini Kit instructions (Catalogue no. 51304), Emerald Amp GT PCR mastermix (Takara) with Code No. RR310A and 1.5\% agarose gel electrophoreses (Sambrook et al., 1989).

\section{RESULTS}

\subsection{The results of bacteriological examination:}

The results of bacteriological examination of examined samples recorded in Table (1) revealed that, a total of $98 \quad(56.0 \%)$ isolates of Staphylococcus species were recovered from 175 samples, including $41 \mathrm{~S}$. aureus (23.4\%); $54 \mathrm{~S}$. epidermidis(30.9\%) and 3 S. chromogenes $(1.7 \%)$ S. aureus were isolated from 41 samples $(23.4 \%)$; represented as $12(34.3 \%)$ from chicken meat followed by $10(28.6 \%)$ from chicken sausage; 8 (22.9\%) from chicken kofta; 6 (17.1\%) from chicken luncheon and 5(14.3\%) from chicken burger. Meanwhile, S. epidermidis were isolated from 54 samples (30.9\%); represented as12 (34.3\%) from chicken kofta followed by11 from 
each samples of chicken meat; chicken burger and chicken luncheon (31.4\%) and $9(25.7 \%)$ from chicken sausage. Moreover, 3S. chromogenes $(1.7 \%)$ were isolated from 2 samples of chicken meat $(5.7 \%)$ and 1 from chicken kofta $(2.8 \%)$ only. The recovered isolates grow well on different media. However, S. aureus showed yellow convex colonies on $7 \%$ salted nutrient agar; yellow colonies (with fermentation of mannitol) surrounded by halo zone on mannitol salt agar medium; while on Baird-Parker agar media showed black shiny colonies (due to tellurite reduction) with yellow halos around them on the surface of the medium and some strains also produce a smaller, clear zone around the colonies due to proteolytic activity. At the same time, the same isolates on blood agar showed a white or yellow, smooth round and shiny colonies with beta and alpha hemolysis and on 7\% salted milk agar they give yellow colonies and turned media to colorless due to lipase enzyme. Meanwhile, $S$. epidermidis showed white, raised, convex colonies on nutrient agar; black colonies on Baird Parker agar; white colonies (without fermentation of mannitol) on Mannitol salt agar; white colonies on Milk salted agar and smooth round, shiny and non -hemolytic colonies on Blood agar. Moreover, S. chromogenes showed black colonies on Baird parker agar; orange colonies (without fermentation of mannitol) on Mannitol salt agar; orange colonies on Milk salted agar and yellow, smooth round, shiny and non-hemolytic colonies on Blood agar. In addition, out of 98 isolated Staphylococcus species strains, 41 strains were coagulase positive, all of them were $S$. aureus strains, and the other isolated Staphylococcal strains (57) were coagulase negative ones.

\subsection{The results of SET -RPLA test:}

The results of SET -RPLA test revealed that 5 strains out of 10 randomly examined strains
$(50.0 \%)$ were enterotoxigenic and classified according to type of toxin into (3A;1 B \& 1C).

\subsection{The results of in vitro sensitivity test:}

The results of in vitro sensitivity test Table (2) showed that, the isolated $S$. aureus were resistant for Methicillin; Oxacillin (73.2\%); Nalidixic acid (65.8\%); Ampicillin (63.4\%); Amoxicillin (61.0\%); Cefotaxime (53.6\%) and Tobramycin (43.9\%). Meanwhile, they were highly sensitive to Gentamycin $(85.3 \%)$; Enrofloxacin and Norfloxacin (82.9\% for each); Lomefloxacin (73.2\%) and Ciprofloxacin (70.7\%). Moreover, they were intermediate sensitive to Sulfatrimethoprim (51.2\%); Neomycin (48.8\%); Streptomycin (43.9\%) and Erythromycin (41.5\%).

\subsection{PCR results:}

PCR results showed that femA; mecA and hlb virulence genes were detected in all 5 studied strains (100.0\%). Meanwhile, ica A was detected in $4(80 \%)$ studied strains; enterotoxin A (sea) was detected in 2 studied strains chicken meat and chicken kofta samples only $(40.0 \%)$ and leukocidin $(p v l)$ virulence gene was detected in 1 studied strains of chicken meat sample only $(20.0 \%)$. Moreover, the femA gene was amplified in all 5 studied S. aureus strains (100.0\%)giving product of $132 \mathrm{bp}$; the mecA gene was amplified in all 5 studied $S$. aureus strains $(100.0 \%)$ giving product of $310 \mathrm{bp}$; the hlb gene was amplified in all 5 studied S. aureus strains (100.0\%) giving product of $496 \mathrm{bp}$; the icaA gene was amplified in 4(80.0\%) $S$. aureus strains giving product of $1315 \mathrm{bp}$; the sea gene was amplified in $2(40.0 \%) S$. aureus strains giving product of $102 \mathrm{bp}$ and the $p v l$ gene was amplified in one $S$. aureus strains of chicken meat sample only (20.0\%) giving product of $433 \mathrm{bp}$ as shown in Fig. (1-6).

Table (1): Incidence of Staphylococcus species strains isolated from examined samples

\begin{tabular}{lllllllll}
\hline \multirow{2}{*}{ Samples } & \multicolumn{8}{c}{ Staphylococcus species } \\
\cline { 2 - 9 } & \multicolumn{2}{c}{ S. aureus } & \multicolumn{3}{c}{ S. epidermidis } & \multicolumn{2}{c}{ S. chromogenes } & \multicolumn{2}{c}{ Total } \\
\cline { 2 - 9 } & NO. & $\%$ & NO. & $\%$ & NO. & $\%$ & NO. & $\%$ \\
\hline Chicken Meat & 12 & 34.3 & 11 & 31.4 & 2 & 5.7 & 25 & 71.4 \\
Chicken Burger & 5 & 14.3 & 11 & 31.4 & 0 & 0.0 & 16 & 45.7 \\
Chicken Luncheon & 6 & 17.1 & 11 & 31.4 & 0 & 0.0 & 17 & 48.6 \\
Chicken Kofta & 8 & 22.9 & 12 & 34.3 & 1 & 2.8 & 21 & 60.0 \\
Chicken Sausage & 10 & 28.6 & 9 & 25.7 & 0 & 0.0 & 19 & 54.3 \\
Total (175) & 41 & 23.4 & 54 & 30.9 & 3 & 1.7 & 98 & 56.0 \\
\hline
\end{tabular}

Percentage in relation to total number of each sample in each row (35 for each sample $\& 175$ for total). 
Table (2): In-Vitro anti-microbial Sensitivity test for isolated S. aureus strains

\begin{tabular}{lllllllll}
\hline Antimicrobial agents & $\begin{array}{l}\text { Disk } \\
\text { concentrations }\end{array}$ & \multicolumn{2}{l}{ Sensitive } & \multicolumn{3}{l}{ Intermediate } & \multicolumn{2}{l}{ Resistant } \\
& & No. & $\%$ & No. & $\%$ & No. & $\%$ & AA \\
\hline Amoxicillin & $25 \mu \mathrm{g}$ & 6 & 14.6 & 10 & 24.4 & 25 & 61.0 & $\mathrm{R}$ \\
Ampicillin & $20 \mu \mathrm{g}$ & 15 & 36.6 & 0 & 0.0 & 26 & 63.4 & $\mathrm{R}$ \\
Cefotaxime & $30 \mu \mathrm{g}$ & 7 & 17.1 & 12 & 29.3 & 22 & 53.6 & $\mathrm{R}$ \\
Ciprofloxacin & $5 \mu \mathrm{g}$ & 29 & 70.7 & 4 & 9.8 & 8 & 19.5 & $\mathrm{~S}$ \\
Enrofloxacin & $5 \mu \mathrm{g}$ & 34 & 82.9 & 3 & 7.3 & 4 & 9.8 & $\mathrm{~S}$ \\
Erythromycin & $15 \mu \mathrm{g}$ & 14 & 34.1 & 17 & 41.5 & 10 & 24.4 & $\mathrm{IS}$ \\
Gentamicin & $10 \mu \mathrm{g}$ & 35 & 85.3 & 4 & 9.8 & 2 & 4.9 & $\mathrm{~S}$ \\
Lomefloxacin & $10 \mu \mathrm{g}$ & 30 & 73.2 & 6 & 14.6 & 5 & 12.2 & $\mathrm{~S}$ \\
Methicillin & $5 \mu \mathrm{g}$ & 2 & 4.9 & 8 & 19.5 & 31 & 75.6 & $\mathrm{R}$ \\
Nalidixic acid & $30 \mu \mathrm{g}$ & 2 & 4.9 & 12 & 29.3 & 27 & 65.8 & $\mathrm{R}$ \\
Neomycin & $30 \mu \mathrm{g}$ & 14 & 34.1 & 20 & 48.8 & 7 & 17.1 & $\mathrm{IS}$ \\
Norfloxacin & $10 \mu \mathrm{g}$ & 34 & 82.9 & 4 & 9.8 & 3 & 7.3 & $\mathrm{~S}$ \\
Oxacillin & $1 \mu \mathrm{g}$ & 3 & 7.3 & 8 & 19.5 & 30 & 73.2 & $\mathrm{R}$ \\
Streptomycin & $\mathrm{S} / 10$ & 7 & 17.1 & 18 & 43.9 & 16 & 39.0 & $\mathrm{IS}$ \\
Sulfa-trimethoprim & $\mathrm{TMP5}$ & 9 & 22.0 & 21 & 51.2 & 11 & 26.8 & $\mathrm{IS}$ \\
Tobramycin & $10 \mu \mathrm{g}$ & 11 & 26.8 & 12 & 29.3 & 18 & 43.9 & $\mathrm{R}$ \\
\hline
\end{tabular}

No.: Number of isolates. \%: Percentage in relation to total number of isolates (41). AA: Antibiogram activity

\section{DISCUSSION}

So far, comparatively little information is available for Methicillin-resistant Staphylococci, particularly MRSA from poultry in general and in particular for MRSA from poultry in Egypt. Therefore, this study was conducted to throw light over the prevalence of Staphylococci with special reference to $S$. aureus and MRSA in retail raw chicken meat and its common products (burger; luncheon; kofta and sausage) sold in markets in Kaliobia Governorate beside the phenotypic characterization of the isolated $S$. aureus strains and detection of some virulence genes in them.

The results of Staphylococcus species strains isolation from examined samples Table (1) cleared that, a total of $98(56.0 \%)$ isolates of Staphylococcus species were recovered from 175 samples, includes 41 S. aureus $(23.4 \%) ; 54$ S. epidermidis (30.9\%) and 3 S. chromogenes (1.7\%). S. aureus were isolated from 41 samples (23.4\%); represented as $12(34.3 \%)$ from chicken meat followed by $10(28.6 \%)$ from chicken sausage; 8 (22.9\%) from chicken kofta; 6 (17.1\%) from chicken luncheon and 5(14.3\%) from chicken burger. Meanwhile, S. epidermidis were isolated from 54 samples (30.9\%); represented as 12 (34.3\%) from chicken kofta followed by11 from each samples of chicken meat; chicken burger and chicken luncheon $(31.4 \%)$ and $9(25.7 \%)$ from chicken sausage. Moreover, 3 S. chromogenes $(1.7 \%)$ were isolated from 2 samples of chicken meat (5.7\%) and 1 from chicken kofta (2.8\%) only.
Nearly similar results for $S$. aureus isolation were recorded by Abdalrahman et al. (2015); Ahmed (2015); Akbar and Anal (2013); Aklilu et al. (2016); Citak and Duman (2011); Feßler et al. (2012.); Lim et al. (2010).

The colonial appearance and the biochemical profile of Staphylococci and isolated S. aureus was similar to those previously reported such as the fermentation of certain sugars or enzymatic reaction as lipase; extracellular pigmentation production (Staphyloxathine) and Staphylocoagulase (Ahmed, 2015; Chandrakanth et al., 2010; Quinn et al., 2002). Moreover, out of 98 isolated Staphylococcus species strains, 41 strains were coagulase positive and all of them were $S$. aureus strains and the other isolated Staphylococcal strains (57) were coagulase negative ones (Table, 2). Nearly similar results were obtained by Chandrakanth et al. (2010); Karmi (2013); Momtaz et al. (2013).

The widespread use of antibiotics has undoubtedly accelerated the virulence of $S$. aureus, by acquiring multiple resistance genes, has become able to survive almost all antibiotic families (Stefani and Goglio, 2010). Several workers have reported the occurrence of multidrug resistant $S$. aureus in poultry (Waters et al., 2011). The invitro sensitivity tests for the isolated $S$. aureus (Table, 2) showed that, the isolated S. aureus were resistant for Methicillin; Oxacillin; Nalidixic acid; Ampicillin; Amoxicillin; Cefotaxime and 


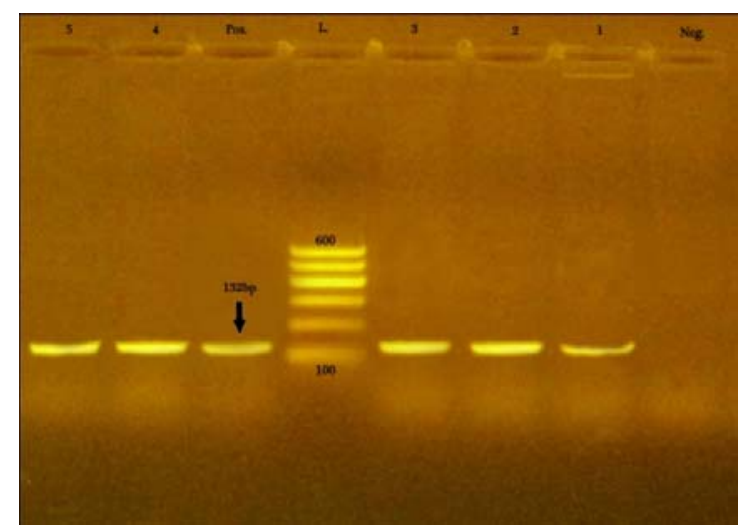

Fig. (1): (femA) gene. Lane L: 100-600 bp DNA Ladder. Neg.: Negative control (Listeria reference: NCINB50007) Pos.: Positive control (S. aureus reference: ATCC25923 at 132 bp). Lane 1; 2; 3; 4 \& 5: S. aureus (Positive).

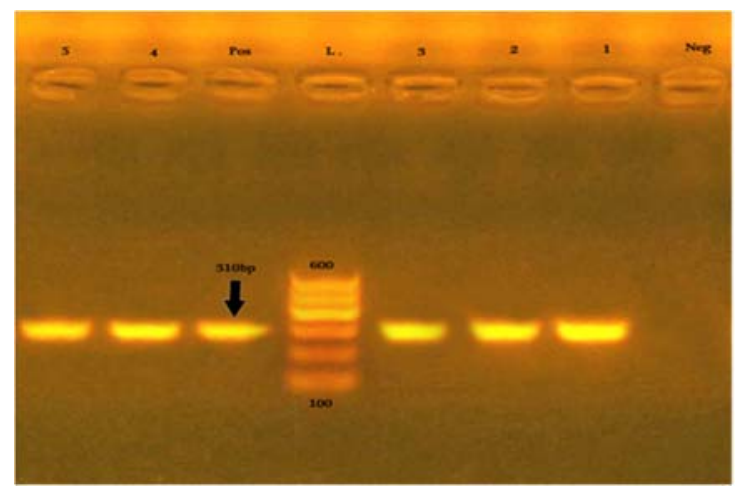

Fig (2): (mecA) gene. Lane L: 100-600 bp DNA Ladder. Neg.: Negative control (Listeria reference: NCINB50007). Pos.: Positive control (S. aureus reference: ATCC25923 at 310 bp). Lane 1; 2; 3; 4 \& 5: S. aureus (Positive).

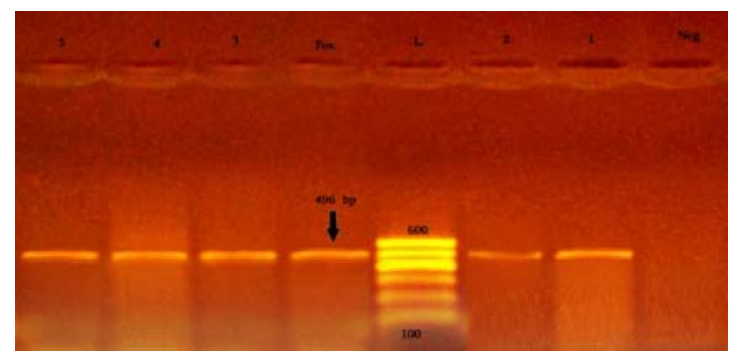

Fig. (3): $\beta$ - hemolysin (hlb) gene. Lane L: 100-600 bp DNA Ladder. Neg.: Negative control (Listeria reference: NCINB50007) Pos.: Positive control (S. aureus reference: ATCC25923 at 496 bp). Lane 1; 2; 3; 4 \& 5: S. aureus (Positive).

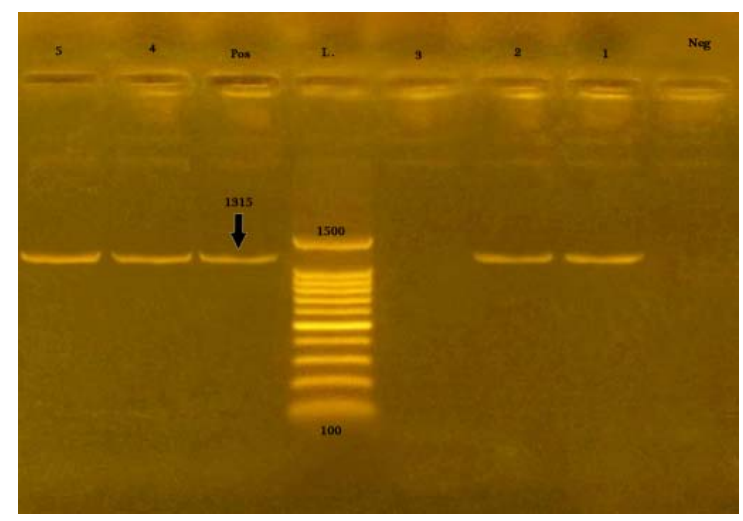

Fig. (4): Intra-cellular adhesion (icaA) gene. Lane L: $100-1500$ bp DNA Ladder. Neg.: Negative control (Listeria reference: NCINB50007) Pos.: Positive control (S. aureus reference: ATCC25923 at $1315 \mathrm{bp}$ ). Lane 1; 2; 4 \& 5: S. aureus (Positive). Lane 3: S. aureus (Negative).

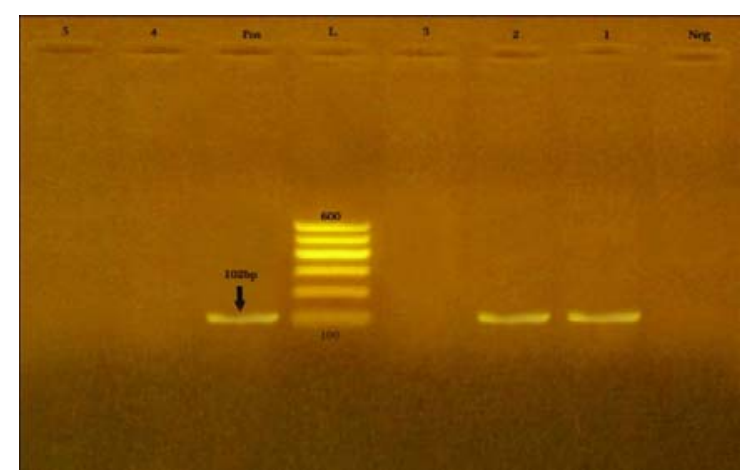

Fig. (5): Enterotoxin A (sea)gene. Lane L: 100-600 bp DNA Ladder. Neg.: Negative control (Listeria reference: NCINB50007). Pos.: Positive control ( $S$. aureus reference: ATCC25923 at 102 bp). Lane 1\& 2: S. aureus (Positive). Lane 3; 4\&5: S. aureus (Negative).

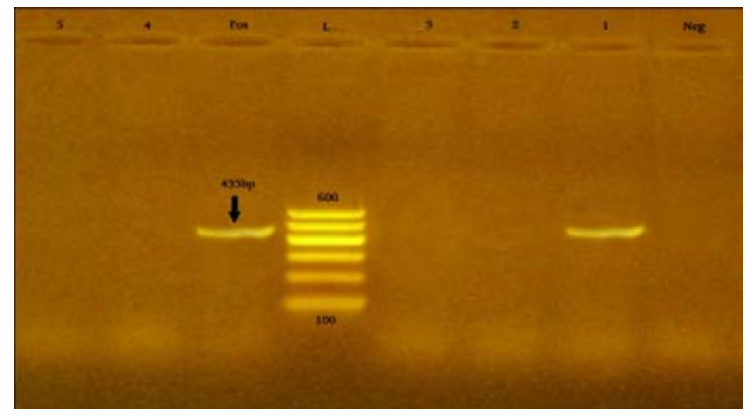

Fig. (6): Leukocidin ( $p v l$ ) gene. Lane L: 100-600 bp DNA Ladder. Neg.: Negative control (Listeria reference: NCINB50007). Pos.: Positive control ( $S$. aureus reference: ATCC25923 at 433 bp). Lane 1: S. aureus (Positive). Lane 2; 3; 4 \& 5: S. aureus (Negative). 
Tobramycin. These results were agreed with AlGhamdi (2012); Otalu et al. (2011); Suleiman et al. (2013) Abdalrahman et al. (2015) and Aklilu et al. (2016). The resistance to methicillin occurred mainly due to the presence of mecA gene on $S$. aureus chromosome that responsible for the production of Penicillin binding protein PBP2a. (Ito et al., 2004). In addition, the results proved that multiple antibiotic resistances are widely spread among isolated strains of $S$. aureus and decided the fact of Mathur and Singh (2005)) that the food chain can be considered as the main route of transmission of antibiotic resistant bacteria between the animal and human populations. Moreover, the isolated $S$. aureus strains were highly sensitive to Gentamycin followed by Enrofloxacin; Norfloxacin; Lomefloxacin and Ciprofloxacin. These results were agreed with Waters et al. (2011) Al-Ghamdi (2012); Suleiman et al. (2013) and Abdalrahman et al. (2015).

$S$. aureus is important pathogen in relation to poultry meat hygiene because of its ability to produce enterotoxins. These enterotoxins are serologically grouped into four major classical types which are SEA, SEB, SEC and SED detected by reversed passive latex agglutination kit (SETRPLA) (Bendahou et al., 2009; Zouharova and Rysanek, 2008). The results of SET- RPLA test revealed that 5 strains out of 10 randomly examined strains $(50.0 \%)$ were enterotoxigenic and classified according to type of toxin into (3A;1 $\mathrm{B}$ and $1 \mathrm{C})$. This result nearly similar to that recorded by Gad (2004) Eshraghi et al. (2009) and Abdalrahman et al. (2015).

The PCR technique is capable of identifying the pathogenic $S$. aureus isolates and identifying the virulence factors of them (Momtaz et al., 2013). The results of PCR for amplification of femA gene in S. aureus isolates (Fig., 1) showed that, the femA gene was amplified in all 5 studied strains $(100.0 \%)$ giving product of $132 \mathrm{bp}$. The results came in harmony with those of Pelisser et al. (2009) and Al-Khafaji and Flayyih (2015.). The results of PCR for amplification of mecA gene in $S$. aureus isolates (Fig., 2) showed that, the mecA gene was amplified in all 5 studied strains $(100.0 \%)$ giving product of $310 \mathrm{bp}$. Similar detection of mecA gene in $S$. aureus strains (MRSA) isolated from chicken meat and its products were recorded by Bunnoeng et al. (2014); Fessler et al. (2011); Lim et al. (2010); Lozano et al. (2009); Momtaz et al. (2013); Weese et al. (2010) and Ahmed (2015).Moreover, mecA alone does not solely confer the methicillin resistance as it was detected among MSSA isolates and studies have shown that fem (factors essential for methicillin-resistance) or the auxiliary genes like fem $\mathrm{A} / \mathrm{B} / \mathrm{X}$ in addition to mecA are important in expression of methicillin resistance, the femABX operon encodes factors which are responsible for the formation of pentaglycine bridges in the cell wall of Staphylococci (Carroll, 2008; Chikkala et al., 2012) and there was correlation between genotypic content of the $f e m A$ and $m e c A$ genes and the phenotypic expression of them when tested by antibiotic disc diffusion method.

In addition, Abdalrahman et al. (2015) failed to detect mecA gene in poultry meat and its products and said that, this might be due to over production of $\beta$-lactamase enzymes or the presence of a variant mecA gene that does not amplify with the available PCR primers. Regarding to the occurrence of $\beta$ haemolysin $(h l b)$ gene in S. aureus isolates.

The obtained result revealed that it was amplified in all 5 studied $S$. aureus strains $(100.0 \%)$ giving product of $496 \mathrm{bp}$ as shown in Fig. (3). These results came in accordance with those recorded by Fessler et al. (2011) and (Abdalrahman et al., 2015). The results of PCR for amplification of icaA gene in S. aureus isolates (Fig.,4) showed that, the icaA gene was amplified in $4(80.0 \%) S$. aureus strains giving product of $1315 \mathrm{bp}$. Similar findings were recorded by Eftekhar and Dadaei (2011) and Fessler et al. (2011).

Staphylococcal enterotoxins are mostly carried on mobile genetic elements, which enable them to transfer horizontally among bacterial populations (Fitzgerald et al., 2001). The results of PCR for amplification of Enterotoxin A (sea) gene in $S$. aureus isolates (Fig., 5) showed that, the sea gene was amplified in $2(40.0 \%) \mathrm{S}$. aureus strains giving product of $102 \mathrm{bp}$. Nearly similar results obtained by Aydin et al. (2011); Madahi et al. (2014); Moon et al. (2007); Zargar et al. (2014) and Abdalrahman et al. (2015). Meanwhile, the results were disagreed with Fessler et al. (2011) who failed to detect sea gene in $\mathrm{S}$. aureus strains isolated from poultry and poultry products. The results of PCR for amplification of Panton-Valentine Leukocidin ( $p v l$ ) gene of S. aureus (Fig.,6) revealed that, the $p v l$ gene was amplified in one $S$. aureus strains of chicken meat sample only $(20.0 \%)$ giving product of $433 \mathrm{bp}$. These results were agreed with those obtained by Abdalrahman et al. (2015); Djoudi et al. (2013). Meanwhile, the results were disagreed with Fessler et al. (2011) who failed to detect pvl gene in $S$. aureus MRSA strains isolated from poultry and poultry products.

Finally, the recorded results demonstrate that, $S$. aureus and MRSA strains are commonly found in retail raw chicken meat and its common products sold in markets in Kaliobia Governorate. Presence of MRSA in raw chickens may pose a potential threat to human health. Measures including good 
manufacturing practice and hazard analysis and critical control points systems should be taken to control the pathogen in poultry production at the farm, processing and retail level.

\section{REFERENCES}

Abdalrahman, L.S., Stanley, A., Wells, H., Fakhr, M.K., 2015. Isolation, Virulence, and Antimicrobial Resistance of Methicillin-Resistant Staphylococcus aureus (MRSA) and Methicillin Sensitive Staphylococcus aureus (MSSA) Strains from Oklahoma Retail Poultry Meats. International journal of environmental research and public health 12, 6148-6161.

Ahmed, H.R., 2015. Isolation and identification of methicillin-resistant S. aureus (MRSA) from poultry meat and poultry products. Kafrelsheikh Vet. Med. J. 13, 57-69.

Akbar, A., Anal, A.K., 2013. Prevalence and antibiogram study of Salmonella and Staphylococcus aureus in poultry meat. Asian Pacific journal of tropical biomedicine 3, 163168.

Aklilu, E., Nurhardy, A.D., Mokhtar, A., Zahirul, I.K., Siti Rokiah, A., 2016. Molecular detection of methicillin-resistant Staphylococcus aureus (MRSA) and methicillin-resistant Staphylococcus epidermidis (MRSE) isolates in raw chicken meat. International Food Research Journal 23, 322-325.

Al-Ghamdi, A.Y., 2012. Incidence of Staphylococcus aureus contamination of marketed Processed Chicken products with special reference to its antibiotics sensitivity collected from Al Baha city markets. Saudi Arabia PAK. J. FOOD SCI. 22, 168-170.

Al-Khafaji, M.H., Flayyih, M.T., 2015. Relationship between methicillin resistance and the presence of femA and mecA genes in coagulase positive and negative staphylococci isolated from milk and cheese World J. Exp.Biosci. 3, 50-56.

Arora, D.R., 2003. Text Book of Microbiology. (Cultural characteristics of Staphylococcus spp (202-2013), 2 ed. Satish Kumar Jain for CBS publishers.

Aydin, A., Sudagidan, M., Muratoglu, K., 2011. Prevalence of staphylococcal enterotoxins, toxin genes and genetic-relatedness of foodborne Staphylococcus aureus strains isolated in the Marmara Region of Turkey. International journal of food microbiology 148, 99-106.

Balaban, N., Rasooly, A., 2000. Staphylococcal enterotoxins. International journal of food microbiology 61, 1-10.

Bendahou, A., Abid, M., Bouteldoun, N., Catelejine, D., Lebbadi, M., 2009. Enterotoxigenic coagulase positive Staphylococcus in milk and milk products, lben and jben, in northern Morocco. Journal of infection in developing countries 3, $169-176$.
Bhargava, K., Wang, X., Donabedian, S., Zervos, M., de Rocha, L., Zhang, Y., 2011. Methicillin-resistant Staphylococcus aureus in retail meat, Detroit, Michigan, USA. Emerging infectious diseases 17, 1135-1137.

Bokarewa, M.I., Jin, T., Tarkowski, A., 2006. Staphylococcus aureus: Staphylokinase. The international journal of biochemistry \& cell biology 38, 504-509.

Bunnoeng , N., Themphachana , M., Pewleang , T., Kongpheng, S., Singkhamanan, K., Saengsuwan, P., Sukhumungoon, P., 2014. High prevalence and molecular characterization of methicillinresistant Staphylococcus aureus isolated from retailed meats, south Thailand. International Food Research Journal 21, 569-576.

Carroll, K.C., 2008. Rapid diagnostics for methicillinresistant Staphylococcus aureus: current status. Molecular diagnosis \& therapy 12, 15-24.

Chandrakanth, K., Virupakshaiah, D.B.M., Gavimath, C.C., Udaykumar, M., Kangralkar, V.A., 2010. Comparative genomics of staphylococcus aureus coagulase gene. Journal of Advanced Bioinformatics Applications and Research 1, 3136.

Chikkala, R., Oommen George, N., S. Ratnakar, K., Natarajan Iyer, R., Sritharan, V., 2012. Heterogeneity in \&lt;i\&gt;femA\&lt;/i\&gt; in the Indian Isolates of \&lt;i\&gt;Staphylococcus aureus\&lt;/i\&gt; Limits Its Usefulness as a Species Specific Marker. Advances in Infectious Diseases 02, 82-88.

Citak, S., Duman, T., 2011. Staphylococcus aureus and coagulase-negative Staphylococcus from raw chicken samples in Turkey: Prevalence and antimicrobial resistance. J Food Agric Environ 9, 156-158.

Cuny, C., Friedrich, A., Kozytska, S., Layer, F., Nubel, U., Ohlsen, K., Strommenger, B., Walther, B., Wieler, L., Witte, W., 2010. Emergence of methicillin-resistant Staphylococcus aureus (MRSA) in different animal species. International journal of medical microbiology : IJMM 300, 109-117.

Dinges, M.M., Orwin, P.M., Schlievert, P.M., 2000. Exotoxins of Staphylococcus aureus. Clinical microbiology reviews 13, 16-34, table of contents.

Djoudi, F., Bonura, C., Benallaoua, S., Touati, A., Touati, D., Aleo, A., Cala, C., Fasciana, T., Mammina, C., 2013. Panton-Valentine leukocidin positive sequence type 80 methicillinresistant Staphylococcus aureus carrying a staphylococcal cassette chromosome mec type IVc is dominant in neonates and children in an Algiers hospital. The new microbiologica 36, 4955.

Eftekhar, F., Dadaei, T., 2011. Biofilm Formation and Detection of IcaAB Genes in Clinical Isolates of Methicillin Resistant Staphylococcus aureus. Iranian Journal of Basic Medical Sciences 14, 132-136. 
Eshraghi, S., Salehipour, Z., Pourmand, M.R., RahimiForushani, A., ZahraeiSalehi, M.T., Agha Amiri, S., Bakhtyari, R., Abedi, M., T.P., Mardani, N., SeyedAmiri, S., SoltanDallal, M.M., 2009. Prevalence of tst, entC, entA and entA/C genes in staphylococcus aureus strains isolated from different foods. Tehran University Medical Journal 67, 470-476.

Fessler, A.T., Kadlec, K., Hassel, M., Hauschild, T., Eidam, C., Ehricht, R., Monecke, S., Schwarz, S., 2011. Characterization of methicillinresistant Staphylococcus aureus isolates from food and food products of poultry origin in Germany. Applied and environmental microbiology 77, 7151-7157.

Feßler, A.T., Wendlandt, S., Ruppelt, A., Kadlec, K., Hassel, M., Cortez de Jäckel, S., Hauschild, T.S., Monecke, S., Slickers , P., Ehricht , R., Schwarz, S., 2012. Methicillin-resistant Staphylococcusaureus (MRSA) from poultry and food ofpoultry origin: molecular characterization and antimicrobial resistance., In: World's Poultry Congress Salvador - Bahia - Brazil, pp. 1-8.

Finegold, S.M., Com, M., W.J. , 1982. Diagnostic microbiology, 6 ed. The C.V. Mosby pany St. Louis, Toronto, London.

Fitzgerald, J.R., Sturdevant, D.E., Mackie, S.M., Gill, S.R., Musser, J.M., 2001. Evolutionary genomics of Staphylococcus aureus: insights into the origin of methicillin-resistant strains and the toxic shock syndrome epidemic. Proceedings of the National Academy of Sciences of the United States of America 98, 8821-8826.

Gad, M.G. 2004. Microbiological evaluation of poultry meat and its product. M.V.Sc. , Sadat University.

Gundogan, N., Devren, A., 2010. Protease and lipase activity of Staphylococcusaureus obtained from meat, chicken and meatball samples. Gu J Sc 23, 381-384.

Hanson, B.M., Dressler, A.E., Harper, A.L., Scheibel, R.P., Wardyn, S.E., Roberts, L.K., Kroeger, J.S., Smith, T.C., 2011. Prevalence of Staphylococcus aureus and methicillin-resistant Staphylococcus aureus (MRSA) on retail meat in Iowa. Journal of infection and public health 4, 169-174.

Hoerlle, J.L., Brandelli, A., 2009. Antimicrobial resistance of Staphylococcus aureus isolated from the intensive care unit of a general hospital in southern Brazil. Journal of infection in developing countries 3, 504-510.

Igarashi, H., Fujikawa, H., Shingaki, M., Bergdoll, M.S., 1986. Latex agglutination test for staphylococcal toxic shock syndrome toxin 1 . Journal of clinical microbiology 23, 509-512.

Karmi, M., 2013. Prevalence of methicillin-resistant Staphylococcus aureus in poultry meat in Qena, Egypt. Veterinary World 6, 711-715.

Lim, S.K., Nam, H.M., Park, H.J., Lee, H.S., Choi, M.J., Jung, S.C., Lee, J.Y., Kim, Y.C., Song, S.W., Wee, S.H., 2010. Prevalence and characterization of methicillin-resistant
Staphylococcus aureus in raw meat in Korea. Journal of microbiology and biotechnology 20, 775-778.

Lin, Y.C., Peterson, M.L., 2010. New insights into the prevention of staphylococcal infections and toxic shock syndrome. Expert review of clinical pharmacology 3, 753-767.

Liu, X.M., Chen, Y., Fan, Y.X., Wang, M.Q., 2006. [Foodborne diseases occurred in 2003--report of the National Foodborne Diseases Surveillance System, China]. Wei sheng yan jiu $=$ Journal of hygiene research 35, 201-204.

Llewelyn, M., Cohen, J., 2002. Superantigens: microbial agents that corrupt immunity. The Lancet. Infectious diseases 2, 156-162.

Losito, P., Vergara, A., Muscariello 1, T., Ianieri, A., 2005. Antimicrobial susceptibility of environmental Staphylococcus aureus strains isolated from a pigeon slaughterhouse in Italy. Poultry science 84, 1802-1807.

Lozano, C., Lopez, M., Gomez-Sanz, E., Ruiz-Larrea, F., Torres, C., Zarazaga, M., 2009. Detection of methicillin-resistant Staphylococcus aureus ST398 in food samples of animal origin in Spain. The Journal of antimicrobial chemotherapy 64 , $1325-1326$.

Madahi, H., Rostami, F., Rahimi, E., Safarpoor Dehkordi, F., 2014. Prevalence of Enterotoxigenic Staphylococcus aureus Isolated From Chicken Nugget in Iran. Jundishapur journal of microbiology 7, e10237.

Mathur, S., Singh, R., 2005. Antibiotic resistance in food lactic acid bacteria--a review. International journal of food microbiology 105, 281-295.

Momtaz, H., Dehkordi, F.S., Rahimi, E., Asgarifar, A., Momeni, M., 2013. Virulence genes and antimicrobial resistance profiles of Staphylococcus aureus isolated from chicken meat in Isfahan province, Iran. The Journal of Applied Poultry Research 22, 913-921.

Moon, J.S., Lee, A.R., Jaw, S.H., Kang, H.M., Joo, Y.S., Park, Y.H., Kim, M.N., Koo, H.C., 2007. Comparison of antibiogram, staphylococcal enterotoxin productivity, and coagulase genotypes among Staphylococcus aureus isolated from animal and vegetable sources in Korea. Journal of food protection 70, 2541-2548.

Normanno, G., La Salandra, G., Dambrosio, A., Quaglia, N.C., Corrente, M., Parisi, A., Santagada, G., Firinu, A., Crisetti, E., Celano, G.V., 2007. Occurrence, characterization and antimicrobial resistance of enterotoxigenic Staphylococcus aureus isolated from meat and dairy products. International journal of food microbiology 115, 290-296.

Otalu, O.J., Junaidu, K., Chukwudi, O.E., Jarlath, U.V., 2011. Multidrug Resistant Coagulase Positive Staphylococcus aureus from Live and Slaughtered Chickens in Zaria Nigeria. Int. J. Poult. Sci. 10 871-875.

Pelisser, M.R., Klein, C.S., Ascoli, K.R., Zotti, T.R., Arisi, A.C., 2009. Ocurrence of Staphylococcus 
aureus and multiplex pcr detection of classic enterotoxin genes in cheese and meat products. Brazilian journal of microbiology : [publication of the Brazilian Society for Microbiology] 40, 145-148

Pinho, M.G., de Lencastre, H., Tomasz, A., 2001. An acquired and a native penicillin-binding protein cooperate in building the cell wall of drugresistant staphylococci. Proceedings of the National Academy of Sciences of the United States of America 98, 10886-10891.

Prescott, M., , H., P. , Klein, D.A., 2005. Microbiology, 6 ed. McGraw Hill., New York U.S.A.

Quinn, P.J., Markey, B.K., Carter, M.E., Donnelly, W.C., Leonard, F.C., Maguire, D., 2002. Veterinary microbiology and microbial disease. Iowa State Univ. Press, , Blackwell Science Ltd,

Saleha, A.A., Zunita, Z., 2010. Methicillin Resistant Staphylococcus aureus (MRSA): An Emerging Veterinary and Zoonotic Pathogen of Public Health Concern and Some Studies in Malaysia. Journal of Animal and Veterinary Advances 9, 1094-1098.

Sambrook, J., Fritsch, E.F., Montias, T., 1989. Molecular Biology. In: Molecular cloning. Laboratory manual, 2 ed. Cold Spring Harbor Laboratory press, USA.

Stefani, S., Goglio, A., 2010. Methicillin-resistant Staphylococcus aureus: related infections and antibiotic resistance. International journal of infectious diseases : IJID : official publication of the International Society for Infectious Diseases 14 Suppl 4, S19-22.

Suleiman, A., Zaria, L.T., Grema, H.A., Ahmadu, P., 2013. Antimicrobial resistant coagulase positive Staphylococcus aureus from chickens in Maiduguri, Nigeria

Sokoto Journal of Veterinary Sciences, 11, 51-55.

Thaker, H.C., Brahmbhatt, M.N., Nayak, J.B., 2013. Isolation and identification of Staphylococcus aureusfrommilk and milk products and their resistance patterns in Anand. Gujarat. Veterinary World J. 6 10-13.

Waters, A.E., Contente-Cuomo, T., Buchhagen, J., Liu, C.M., Watson, L., Pearce, K., Foster, J.T., Bowers, J., Driebe, E.M., Engelthaler, D.M., Keim, P.S., Price, L.B., 2011. MultidrugResistant Staphylococcus aureus in US Meat and Poultry. Clinical infectious diseases : an official publication of the Infectious Diseases Society of America 52, 1227-1230.

Weese, J.S., Avery, B.P., Reid-Smith, R.J., 2010. Detection and quantification of methicillinresistant Staphylococcus aureus (MRSA) clones in retail meat products. Letters in applied microbiology 51, 338-342.

Zargar, M.H.S., Doust, R.H., Mobarez, A.M., 2014. Staphylococcus aureus Enterotoxin A Gene Isolated From Raw Red Meat andPoultry in Tehran. Iran Int. J. Enteric Pathog 2, 1-5.

Zouharova, M., Rysanek, D., 2008. Multiplex PCR and RPLA Identification of Staphylococcus aureus enterotoxigenic strains from bulk tank milk. Zoonoses and public health 55, 313-319. 